\title{
COMMENTARY
}

\section{RIFLE is alive: long live RIFLE}

\author{
Zaccaria Ricci* \\ See related research by Wlodzimirow et al., http://ccforum.com/content/16/5/R200
}

\begin{abstract}
Diagnosis and classification of acute kidney injury was addressed systematically only 8 years ago when the classification called RIFLE (acronym of Risk, Injury, Failure, Loss of function and End stage Kidney disease describing progressive severity of renal damage) was created. Since then, several studies have tried to apply, validate, criticize and modify this initial scheme: as a matter of fact, RIFLE is today one of the most appreciated and utilized medical classification systems worldwide. After an initial period of epidemiological research, it is acceptable to apply it now at the bedside, following both urine output and creatinine criteria, with the purpose of routinely monitoring renal function of critically ill patients.
\end{abstract}

\section{The past}

The RIFLE criteria were born in Vicenza (Italy) back in 2004 when a group of smart clinicians realized that none of them was able to provide the same definition of acute kidney injury (AKI), formerly known as acute renal failure [1]. Aware of their unique expertise in the field of renal disorders in critically ill patients, these pioneers had the winning idea of creating the first definition of acute renal disease on the basis of one commonsense rule: to work, such a definition has to be universally utilized and, hence, based on just two, simple and easily available parameters, serum creatinine and urine output. A second innovation was to consider renal damage as a spectrum of severities that could be easily classified (even though only by convention rather than by strict clinical relevance) into three classes (risk, injury and failure) and two outcomes (loss of function and end stage kidney disease). The final chapter of this story is that hundreds of authors tried to apply and eventually validated the

*Correspondence: z.ricci@libero.it

Pediatric Cardiac Anesthesia/Intensive Care Unit, Department of Pediatric Cardiology and Cardiac Surgery, Bambino Gesù Children's Hospital, IRCCS, Piazza S. Onofrio 4, 00165, Rome, Italy
RIFLE criteria with epidemiological studies on AKI [2]. It has to be noted that a 'definition' should not be confounded with the concept of 'aetiological diagnosis': RIFLE criteria were not born to identify the cause of AKI but only to identify it in a standardized way. Consequently, a renewed interest in AKI diagnosis, prevention and treatment was raised by this huge amount of standardized information [3]: today, awareness of actual AKI incidence and of its lethal effects (even after milder forms of renal impairment) in several clinical settings has dramatically increased and some centers have already implemented RIFLE score in their databases and medical records [4]. The other side of the coin was that, even if sometimes unintentionally, each study tended to slightly modify the original RIFLE definition in order to best adapt it to its research [5]. To cite just a few, in retrospective epidemiological studies, urine output (UO) criteria have been discarded because this kind of data is not easily achievable in databases [5]. In other cases, baseline creatinine (essential in RIFLE scoring) has been argued about, estimated or not evaluated because it is not available for all patients [5]. Some authors have finally verified the RIFLE criteria on large cohorts of critically ill patients for very short periods of time, such as the first 24 hours after ICU admission [5]. It must be acknowledged that this variation may have significantly affected findings on AKI prevalence, incidence and prognosis.

\section{The present}

In the previous issue of Critical Care Wlodzimirow and coworkers [6] show in a prospective observational study how RIFLE criteria should be correctly used. They substantially simulated routine use of RIFLE classification with UO criteria (RIFLE serum creatinine $(\mathrm{sCr})+\mathrm{UO}$ ) and without UO criteria (RIFLE sCr) for a whole week after ICU admission. The authors also included patients without known pre-ICU creatinine and estimated it, as suggested by RIFLE, with the Modification of Diet in Renal Disease formula [1]. According to their findings, the use of RIFLE without the urine criteria significantly underscores the incidence and grade of AKI, significantly delays the diagnosis of AKI and underestimates mortality rates. Remarkably, the accurate analysis by Wlodzimirow and colleagues reveals that AKI diagnosis during the first 
week of ICU admission was doubled by RIFLE sCr+UO, probably due to transient periods of oliguria not followed by increases in creatinine level. Interestingly, Prowle and coauthors [7], driven by a similar idea, recently concluded that oliguria $(<0.5 \mathrm{ml} / \mathrm{kg} / \mathrm{h})$ is a modest predictor of subsequent creatinine increase, especially when lasting for shorter periods of time ( $<12$ hours). This aspect should be taken into account in clinical practice and, obviously, AKI should not be classified after 30 minutes of anuria: as a matter of fact, the UO-Risk class of RIFLE needs at least 6 hours of oliguria before the criterion is reached. However, UO is by far one of the earliest clinical signs of acute renal impairment. Furthermore, we know that subclinical AKI, either identified by pathological levels of early biomarkers (such as neutrophil gelatinaseassociated lipocalin) [8], or by transient azotemia (defined as rapidly recovering AKI with return to no-AKI RIFLE class within 72 hours of onset) [9] is indeed associated with poor outcomes. On the other hand, creatinine alone may underscore the severity of AKI, due to its delayed increase in the setting of rapidly evolving AKI, especially in patients with fluid overload and hemodilution [10]. Alertness to milder forms of AKI, those with the potential of worsening and that should be targeted by specific treatment, is one of the most important goals of the RIFLE classification.

\section{Conclusion: the future?}

RIFLE is an imperfect, questionable, conventional, practical definition. The original aim of its creators was not to predict mortality or to associate it with any hard clinical outcome, but to find a common language on AKI diagnosis. Still, clinical validation was performed and it achieved satisfactory results. New criteria $[11,12]$ have been proposed as substitutes of RIFLE in an attempt to improve the sensitivity and specificity of the AKI identification: they apparently failed to achieve significant results [5]. It should be considered whether a fine-tuning of the original RIFLE criteria might have worked better. Moreover, as an exclusively personal opinion, RIFLE customizations and new classifications might have induced confusion and uncertainty in readers and clinicians, those originally intended to be the main users of such criteria. It must be remembered that the acute respiratory distress syndrome definition, born under the same rationale as RIFLE (but many years earlier), has been recently modified after about two decades of worldwide application [13,14].

In conclusion, the time has come to apply RIFLE clinically, at the bedside, applying both UO and creatinine criteria [9], with the purpose of longitudinally monitoring the renal condition of critically ill patients.

The next step of RIFLE will be to understand if it is actually possible to standardize AKI prevention strategies or therapeutic approaches to the different severity classes: early attempts have already been performed with success [15].

\section{Abbreviations}

AKI, acute kidney injury; RIFLE, Risk, Injury, Failure, Loss of function and End stage Kidney disease; $\mathrm{s} C r$, serum creatinine; UO, urine output.

\section{Competing interests}

The author declares that they have no competing interests.

\section{Published: 29 November 2012}

\section{References}

1. Bellomo R, Ronco C, Kellum JA, Mehta RL, Palevsky P; Acute Dialysis Quality Initiative workgroup: Acute renal failure - definition, outcome measures, animal models, fluid therapy and information technology needs: the Second International Consensus Conference of the Acute Dialysis Quality Initiative (ADQI) Group. Crit Care 2004, 8:R204-212.

2. Ricci Z, Cruz D, Ronco C: The RIFLE criteria and mortality in acute kidney injury: A systematic review. Kidney Int 2008, 73:538-546.

3. Basso F, Ricci Z, Cruz D, Ronco C: International survey on the management of acute kidney injury in critically ill patients: year 2007. Blood Purif 2010, 30:214-220.

4. Colpaert K, Hoste E, Van Hoecke S, Vandijck D, Danneels C, Steurbaut K, De Turck F, Decruyenaere J: Implementation of a real-time electronic alert based on the RIFLE criteria for acute kidney injury in ICU patients. Acta Clin Belg Supp/ 2007, 2:322-325.

5. Cruz DN, Ricci Z, Ronco C: Clinical review: RIFLE and AKIN - time for reappraisal. Crit Care 2009, 13:211.

6. Wlodzimirow KA, Abu-Hanna A, Slabbekoorn M, Chamuleau RA, Schultz MJ, Bouman CS: A comparison of RIFLE with and without urine output criteria for acute kidney injury in critically ills. Crit Care 2012, 16:R200.

7. Prowle JR, Liu YL, Licari E, Bagshaw SM, Egi M, Haase M, Haase-Fielitz A, Kellum JA, Cruz D, Ronco C, Tsutsui K, Uchino S, Bellomo R: Oliguria as predictive biomarker of acute kidney injury in critically ill patients. Crit Care 2011, 15:R172

8. Haase M, Devarajan P, Haase-Fielitz A, Bellomo R, Cruz DN, Wagener G, Krawczeski CD, Koyner JL, Murray P, Zappitelli M, Goldstein SL, Makris K, Ronco C, Martensson J, Martling CR, Venge P, Siew E, Ware LB, Ikizler TA, Mertens PR: The outcome of neutrophil gelatinase-associated lipocalinpositive subclinical acute kidney injury: a multicenter pooled analysis of prospective studies. J Am Coll Cardio/ 2011, 57:1752-1761.

9. Uchino S, Bellomo R, Bagshaw SM, Goldsmith D: Transient azotaemia is associated with a high risk of death in hospitalized patients. Nephrol Dial Transplant 2010, 25:1833-1839.

10. Macedo E, Bouchard J, Soroko SH, Chertow GM, Himmelfarb J, Ikizler TA, Paganini EP, Mehta RL; Program to Improve Care in Acute Renal Disease Study: Fluid accumulation, recognition and staging of acute kidney injury in critically-ill patients. Crit Care 2010, 14:R82

11. Mehta RL, Kellum JA, Shah SV, Molitoris BA, Ronco C, Warnock DG, Levin A Acute Kidney Injury Network: Acute Kidney Injury Network: report of an initiative to improve outcomes in acute kidney injury. Crit Care 2007, 11:R31.

12. The ad-hoc working group of ERBP: Fliser D, Laville M, Covic A, Fouque D, Vanholder R, Juillard L, Van Biesen W: A European Renal Best Practice (ERBP) position statement on the Kidney Disease Improving Global Outcomes (KDIGO) Clinical Practice Guidelines on Acute Kidney Injury: Part 1: definitions, conservative management and contrast-induced nephropathy. Nephrol Dial Transplant 2012 [Epub ahead of print].

13. Bernard GR, Artigas A, Brigham KL, Carlet J, Falke K, Hudson L, Lamy M, Legall JR, Morris A, Spragg R: The American-European Consensus Conference on ARDS. Definitions, mechanisms, relevant outcomes, and clinical trial coordination. Am J Respir Crit Care Med 1994, 149:818-824.

14. ARDS Definition Task Force, Ranieri VM, Rubenfeld GD, Thompson BT, Ferguson ND, Caldwell E, Fan E, Camporota L, Slutsky AS: Acute respiratory distress syndrome: the Berlin Definition. JAMA 2012, 307:2526-2533.

15. Colpaert K, Hoste EA, Steurbaut K, Benoit D, Van Hoecke S, De Turck F, Decruyenaere J: Impact of real-time electronic alerting of acute kidney injury on therapeutic intervention and progression of RIFLE class. Crit Care Med 2012, 40:1164-1170.

doi:10.1186/cc11851

Cite this article as: Ricci Z: RIFLE is alive: long live RIFLE. Critical Care 2012, 16:182. 